\title{
Aplicación de los principios de la imputación objetiva en la actividad médica ${ }^{1}$
}

\author{
Hernando A. Hernández Quintero* \\ Recepción: 05/07/2018 • Aprobación: 28/09/2018 • Publicación: 19/12/2018

\section{Resumen} \\ El presente artículo presenta un análisis de la responsabilidad penal que se puede \\ endilgar a los profesionales de la medicina por actos realizados en el ejercicio de \\ su profesión, con una visión desde la teoría de la imputación objetiva.
}

\section{Palabras claves}

Acto médico, riesgo permitido, principio de confianza, consentimiento informado, homicidio, lesiones personales.

\begin{abstract}
The following article presents the reader with an analysis of the criminal responsibility that could be charged upon professionals of the medical field, due to actions related with the exercise of their profession, from the perspective of the objective imputation.
\end{abstract}

\section{Keywords}

Medical conduct, allowed risk, principle of trust, informed consent, homicide, personal injuries.

\footnotetext{
${ }^{1}$ Los aspectos básicos de la presente contribución fueron tratados en el artículo "La responsabilidad penal médica: una visión en la legislación colombiana y argentina".

* Abogado de la Universidad Incca de Colombia. Magíster en Derecho Penal y Criminología de la Universidad Externado de Colombia y doctor por la misma Universidad. Especialista en Derecho Penal de la Universidad de Salamanca (España). Especialista en Legislación Financiera de la Universidad de los Andes. Profesor Titular de la Universidad de Ibagué y de Posgrado en las Universidades Externado de Colombia, Libre de Colombia y Pontificia Bolivariana de Medellín. Director del grupo de investigación Zoon Politikon. Contacto: hernando.hernandez@unibague.edu.co
}

\section{Para citar este artículo}

Hernández Quintero, H. (2018). Aplicación de los principios de la imputación objetiva en la actividad médica. Dos mil tres mil, 20(1), 59-85. doi: https://doi.org/10.35707/dostresmil/20103 


\section{Introducción}

Uno de los temas de mayor preocupación para el derecho penal en la actualidad lo constituye la responsabilidad penal que pueda deducirse a los profesionales de la medicina por actos realizados en ejercicio de esta actividad permitida por el Estado, y que es de vital importancia en el desarrollo de la sociedad. En el pasado, pocos eran los sucesos que tramitaban por la jurisdicción penal por este motivo, bien por la falta de conocimiento de los afectados, o bien por no contar, como ahora, con una gran divulgación de los derechos de los ciudadanos, que particularmente en Colombia se ha dado a partir de la Constitución de 1991. En principio, las reclamaciones fueron realizadas por vía de la justicia contenciosa administrativa y los tribunales de ética médica de los diferentes Estados. Esta práctica se ha extendido, y de qué manera, al Derecho penal, y obliga a los fiscales, jueces y abogados litigantes a estudiar la problemática y a los galenos, a conocer más a fondo los riesgos a que pueden verse expuestos en su diario quehacer profesional.

También es evidente que, tradicionalmente, los asuntos se resolvían exclusivamente con los criterios de la dogmática penal clásica, esto es, los principios del causalismo. Con los evidentes avances del derecho penal, que superan incluso los estrechos linderos de los estatutos penales, se viene abriendo camino el apelar a los contenidos de la imputación objetiva y los conceptos del riesgo permitido, el principio de confianza, el incremento del riesgo y la prohibición de regreso, con los que se procura fijar los alcances del tipo penal (Quijano Gómez, 2012, p. 55).

Por lo anotado, en el presente escrito estableceremos, en principio, qué se entiende por acto médico, para luego abordar los problemas que se detectan en ejercicio del mismo, los modos tradicionales de enfrentar sus consecuencias y los aportes de la imputación objetiva, en procura de solucionar en mejor forma los diferentes casos que se presentan en tan importante actividad. 


\section{El acto médico}

El acto médico ha sido definido con acierto por la doctora Paula Inés Argnani (2013) como una intervención, directa o indirecta, del médico o de sus colaboradores, en el cuerpo o psiquis del paciente para diagnosticar, pronosticar y tratar sus enfermedades o para recuperar, conservar y preservar la salud.

El acto médico está compuesto por las etapas de diagnóstico, tratamiento y postratamiento. Cada una de ellas debe analizarse en forma separada para evidenciar los posibles riesgos a que se ve sometido el paciente.

Si bien se ha aceptado que la actividad médica es de medios y no de resultados, en las intervenciones de los profesionales de la salud pueden presentarse diferentes situaciones que van desde las omisiones hasta la conducta desviada del ejercicio de la actividad profesional, en lo que se ha conocido como mala praxis. Tales conductas pueden producir efectos negativos para la vida del paciente, que ocasionen su muerte o lesiones en su salud o su psiquis. Como consecuencia, el profesional debe responder por un delito de homicidio o lesiones personales culposas, en los términos de los artículos 109 y 120 del Código Penal colombiano.

Como es sabido, en la legislación colombiana, la modalidad culposa del delito se refiere al actuar con violación del deber objetivo de cuidado bien por imprudencia, negligencia o impericia, o bien, por inobservancia de reglamentos o deberes a su cargo. Siguiendo las corrientes tradicionales de la dogmática penal, bastaba con establecer el nexo causal entre la conducta del agente y el resultado que se investigaba para deducir responsabilidad penal al ciudadano, desde luego, acreditando su responsabilidad a título de dolo, culpa o preterintención.

En las nuevas corrientes, imbuidas de los principios del funcionalismo, se introducen otros criterios que apuntan a la responsabilidad del sujeto conforme al rol que le corresponde desempeñar en la sociedad y la violación de sus deberes, ya sea que se trate de los generales que corresponden a todo ciudadano o de los particulares quele son asignados por especiales condiciones, 
en lo que el profesor Jakobs ha denominado deberes generales e institucionales. De esta forma, se afirma con razón que la imputación objetiva parte de una premisa fundamental: demostrada la causalidad, se le puede imputar al sujeto la lesión o puesta en peligro del bien jurídico cuando ha creado un riesgo jurídicamente desaprobado, que se concreta en la producción de un resultado típico. Como criterios de imputación se reconocen: la disminución y elevación del riesgo; el riesgo permitido; el fin de protección de la norma; el principio de insignificancia; la creación de un riesgo jurídicamente relevante; la realización del peligro inherente a la acción base y la conducta alternativa conforme al derecho (Montealegre Lynett, 1988).

Es a partir de estas nuevas nociones como abordaremos la responsabilidad penal médica a que se refiere el presente trabajo. Para ello, es preciso analizar, en primer lugar, los conceptos de riesgo permitido, principio de confianza y elevación del riesgo, entre otros.

\section{El riesgo permitido}

Es evidente que el desarrollo tecnológico de la sociedad trae consigo un sinnúmero de riesgos que debemos asumir, so pena de paralizar las actividades diarias y el incontenible avance de los países (por ejemplo, la producción de automóviles veloces, la construcción de grandes edificaciones y las intervenciones quirúrgicas complejas). No es concebible hoy una sociedad libre de riesgos (a tal punto que se habla, justamente de la "sociedad del riesgo"), por lo que en muchos casos, en lugar de intentar eliminarlos, hemos entonces de aprender a convivir con ellos, tolerándolos como permitidos, en razón a que son inherentes a determinadas actividades.

Se debe a Welzel el primer impulso para considerar que existen algunos comportamientos que aparentemente producen una lesión, pero que no merecen reproche alguno por ser socialmente aceptados, a los cuales el autor denominó "conductas socialmente adecuadas". Por esta vía, como lo advierte Reyes Alvarado (2005), se solucionaron desde el finalismo múltiples casos complejos que escapaban a la regulación a través de la intencionalidad de la conducta (p. 207). 
Se ha entendido por riesgo permitido una conducta que crea un riesgo jurídicamente relevante, pero que de modo general (independientemente del caso concreto) está autorizado y por ello, a diferencia de las causas de justificación, excluye ya la imputación al tipo objetivo (Roxin, 1997). Se trata, como lo señala Reyes Alvarado (2005) de todo aquel riesgo que permanece aún con el cumplimiento de las normas de cuidado que deben acompañar la ejecución de toda actividad peligrosa socialmente admitida. Se cita como prototipo de este riesgo permitido la conducción de automóviles cuando se observan todas las reglas establecidas para la circulación automovilística.

En lo que respecta a la materia de nuestro estudio, es evidente que la actividad médica constituye una clásica actividad permitida que genera un riesgo permitido. Como lo advierte Bernate Ochoa (2010), si bien muchos de los procedimientos médicos se encuentran ampliamente decantados (piénsese en el caso de la cirugía general, en donde la realización de una apendicectomía o una colecistectomía está claramente establecida), es inevitable que su ejercicio se produzcan resultados lesivos para los usuarios del sistema de salud.

En tales condiciones, antes que proscribir el ejercicio de la medicina, lo aconsejable es regular esta profesión, con el fin de minimizar la posibilidad de riesgos y de que los mismos se concreten en resultados lesivos para los bienes jurídicos de la vida y la integridad personal.

De esta forma, el ejercicio de la medicina se ha venido reglamentando por vía legal. Por ejemplo, en Colombia, con la Ley 23 de 1981, "por la cual se dictan normas en materia de ética médica" y el Decreto 3380 de 1981 que la reglamenta.

Asimismo, es necesario acudir a la lex artis, entendida esta como la codificación de las pautas de comportamiento que el ejercicio de una actividad profesional va decantando, las cuales orientan el correcto desempeño de la función. Como lo sostiene Carlos Mario Molina Arrubla (1998):

Esa lex artis, que puede ser indicada como la "ley propia del arte que se ejecuta", 
no es otra cosa que aquellos mandatos o reglas específicas, que deben ser observadas dentro de determinado arte o técnica, a efectos de poder lograr o conseguir unos determinados resultados: en el terreno que nos ocupa, esto es, el de la medicina, puede decirse que esa lex artis se encuentra conformada por las reglas técnicas que deben seguirse con miras a la obtención de los resultados deseados, esperados y perseguidos, no solo por el paciente sino también por el médico, en beneficio de la salud, la integridad y la vida del primero. ( p. 203)

Desde ya, es prudente precisar que la violación a la lex artis no constituye por sí sola delito, sino que es necesario probar que su violación causó efectivamente un resultado lesivo para el paciente.

Finalmente, cuando no se cuenta con parámetros legales (reglamentos) o con la experiencia decantada de la vida (lex artis), se aconseja el juicio comparativo o baremo, que consiste en "comparar la conducta que siguió el sujeto, con la que hubiera seguido en el mismo ámbito de relación un hombre prudente y diligente" (Montealegre Lynett, 1988, p. 49) o, como lo advierte Bernate Ochoa (2010), el funcionario judicial debe ponderar la conducta del médico frente a la que hubiere desarrollado otro profesional con las mismas cualidades, experiencia y conocimientos que quien efectivamente desarrolló la conducta que se enjuicia.

La Corte Suprema de Justicia de Colombia ha concluido que "el límite entre el riesgo permitido y el desaprobado lo brindan los protocolos de la lex artis y el cumplimiento del deber de información que se concreta en el consentimiento informado" (Sala de Casación Penal, 11 de abril de 2012, Proceso 33920).

\section{El riesgo permitido y los deberes del profesional de la salud en cada una de las fases del acto médico}

\section{a. Diagnóstico}

En el diagnóstico, primera fase del acto médico, es obligación del profesional realizar la observación del usurario del servicio en forma directa. Empero, 
es posible aceptar el principio de confianza en dos eventos: el diagnóstico realizado por una autoridad científica y el realizado por un especialista. Del primero, puede afirmarse en el caso en que el alumno confía en la valoración de su profesor y del segundo, cuando quien no es especialista acepta el criterio de un experto en el tema del que se trata la consulta.

En esta etapa es también indispensable que se realicen al paciente todos los exámenes tecnológicos posibles, utilizando el tiempo necesario para formarse adecuadamente una idea de la situación actual de quien consulta. Ninguna razón, por ejemplo la económica, es excusa para obviar estos exámenes. Si la entidad en que labora el médico no cuenta con los equipos necesarios para estos exámenes, la responsabilidad recaerá sobre la entidad. De otra parte, las pruebas que se realicen deben ser aquellas que pongan en menor riesgo al paciente.

Sobre este tema bien puede recrearse el caso analizado por la Cámara Nacional de Apelaciones en lo Civil, Sala B, de la República Argentina, en sentencia del 23 de mayo de 2007, en la que un médico atiende a un paciente que presenta un dolor lumbar. El médico le sugiere practicar una mielorradiculografía, y se le inyecta en la médula una sustancia de contraste que le originó paresia de los miembros inferiores e intensas algias, claudicación de la marcha, limitación funcional marcada, disfunción sexual, síndrome depresivo y pérdida del sueño. En el proceso se condena al galeno por cuanto este hubiera podido utilizar como método diagnóstico una resonancia por imágenes, tratamiento inocuo y no invasivo, todo lo contrario al que efectivamente se le aplicó al paciente y que desencadenó una lesión de su integridad física (Bernate Ochoa, 2010, p. 113).

Es claro también que cuando el caso no corresponda a la especialidad del médico, este debe remitirlo a un especialista. Desconocer esta posibilidad puede conducir al profesional a una culpa por asunción de riesgo, siempre y cuando se demuestre que el resultado nocivo se había podido evitar cuando hubiere sido tratado por un especialista. Como lo deja sentado Welzel (citado por Montealegre Lynett, 1988, p. 54): "El que no es capaz de 
realizar correctamente la acción planeada debe omitirla; para él la conducta correcta, o el cuidado necesario en el tráfico, es la omisión de la acción..." Naturalmente puede presentarse un estado de necesidad cuando un médico general atiende a un paciente por complicaciones cardíacas en la zona rural donde no se cuenta con un especialista.

Otro deber inexcusable es el de elaborar la historia clínica (art. 34 de la Ley 23 de 1981), que se trata de un documento privado, sometido a reserva, en que encuentran respaldo probatorio todas las actuaciones sobre el paciente. Asimismo, es obligación del médico mantener el secreto profesional y suministrar al paciente el informe sobre el estado de su salud, los riesgos en que se encuentra su integridad, las alternativas de tratamiento, los riesgos que las mismas conllevan, igual que los riesgos que se suscitan por la no aplicación del tratamiento. Sobre este tema volveremos al hablar de consentimiento informado.

Un reciente fallo de la Corte Suprema de Justicia de Colombia nos permite contextualizar lo expresado previamente. En efecto, un juzgado de la ciudad de Cali condenó por el delito de lesiones personales culposas (deformidad física de carácter permanente) a un patólogo por el error en el diagnóstico de una paciente y por no haber realizado otros exámenes de comprobación. El patólogo reportó el hallazgo de carcinoma ductal de tipo tubular con cambios fibroquísticos en el tejido mamario de una paciente. El resultado no fue confirmado ni descartado mediante la práctica de exámenes adicionales, por ejemplo, el estudio inmunohistoquímico. El oncólogo, con base en ese diagnóstico determinó que el tratamiento que se debía seguir era la extirpación total del seno derecho con vaciamiento de ganglios. Un nuevo examen del tejido extraído, realizado por otra patóloga, estableció que no se trataba de una lesión maligna, sino de una adenosis esclerosante, lesión de naturaleza benigna.

El Tribunal Superior de Cali confirmó la sentencia, modificando la pena. La Corte Suprema de Justicia no casó la sentencia y aprovechó para 
realizar un estudio detenido de los principios de la imputación objetiva y su aplicación en los delitos culposos. Se concluyó que en este evento el patólogo incrementó el riesgo jurídicamente desaprobado por asunción de un riesgo no permitido en el ejercicio de la lex artis de la patología y en su posición de garante de la paciente. El alto tribunal de Justicia precisó:

El médico patólogo, doctor $\mathrm{X}$, asumió la posición de garante respecto de la paciente. Y, en virtud de lo normado en el numeral 1 del artículo 25 del Código Penal y en los términos del artículo 10 de la Ley 23 de 1981, que consagra: "El médico dedicará a su paciente el tiempo necesario para hacer una evaluación adecuada de su salud e indicar los exámenes indispensables para precisar el diagnóstico y prescribir la terapéutica correspondiente".

En conclusión, un diagnóstico inicial de carcinoma, sin procurar su confirmación, constituía de por sí, en este caso particular, una elevación del riesgo no amparado por la lex artis, pues los métodos y prácticas propios de la patología enseñan que nada tiene de raro que la lesión maligna en realidad no lo sea" (Sala de Casación Penal, 29 de junio de 2016, Proceso 41 245).

De esta forma, se incrementó el riesgo jurídicamente desaprobado. En resumen, en el caso citado, el patólogo fue condenado como coautor de la conducta punible, por violación de la posición de garante, lo que presupone haber dejado de actuar, teniendo el deber legal de evitar el resultado; esto es, una infracción del deber especial de impedir el resultado dañoso.

\section{b. Tratamiento}

Una segunda etapa del acto médico la constituye el tratamiento, estadio en el cual se realiza la intervención directa sobre el cuerpo del paciente. En esta fase el profesional también está obligado a observar algunos deberes legales y de la lex artis. Su incumplimiento genera riesgos jurídicamente desaprobados $y$, en caso de concretarse un resultado lesivo para el paciente, dará lugar a la imputación objetiva de los mismos. 
Esos deberes son el deber de mantenerse dentro del riesgo permitido; el deber de mantenerse dentro de la lex artis; el deber de evitar acciones peligrosas y la realización de acciones de salvamento.

En cuanto al primero, una vez conocido el diagnóstico y la situación real de la salud del paciente, el profesional de la medicina debe realizar el procedimiento que considere adecuado, previendo las fuentes de riesgo permitido, es decir, la normatividad y la lex artis. Esto incluye las guías y protocolos de manejo, y en su defecto, la literatura científica. Aquí se destaca, por ejemplo, la prohibición de aplicar al paciente métodos experimentales, salvo que no exista normatividad o protocolo al respecto y siempre que se cuente con el consentimiento informado.

Por esta vía arribamos al segundo deber, que consiste fundamentalmente en evitar acciones peligrosas, por ejemplo, utilizar un instrumento en forma inadecuada produciendo daños en el cuerpo del paciente. La realización de acciones de salvamento consiste en la obligación para el profesional de adoptar las medidas necesarias cuando en el desarrollo de un procedimiento sobrevengan situaciones que pongan en peligro la vida de la persona. La discusión se presenta cuando la intervención no está dentro de la especialidad del médico tratante. Algunos piensan que estamos, entonces, frente a un típico caso de estado de necesidad, pero otros autores niegan esta posibilidad por la inexistencia de colisión de derechos.

\section{c. Postratamiento}

Consiste en la obligación del médico de efectuar asistencia y seguimiento a la evolución de la salud de la persona que ha intervenido. Quien omita este compromiso genera un riesgo jurídicamente desaprobado y en el evento de presentarse un desenlace fatal para el paciente, será responsable del mismo. Desde luego, en este caso es necesario contar con el debido cuidado del propio paciente y el cumplimiento estricto de las indicaciones del profesional. 
Sobre este tema, se recuerda en Colombia el proceso en el cual se condenó a un cirujano estético como autor del delito de lesiones personales culposas, de acuerdo con los siguientes hechos citados en el fallo:

El 22 de julio de 2003, en la clínica Santillana de Cali, una ciudadana se sometió a una intervención quirúrgica de implantación mamaria, inyección glútea y lipoescultura, que fue practicada por un cirujano estético. Al tercer día del posoperatorio la paciente exhibía extensas zonas de enrojecimiento y úlceras de la piel del abdomen (eritema y epidermólisis), a las que se sumaron un intenso dolor, fiebre, vómito y malestar general. El médico comentó que se trataba de un proceso normal de recuperación y ordenó diez sesiones de cámara hiperbárica.

El proceso de sufrimiento de la piel —que inició probablemente con el trauma causado por la liposucción superficial que habría ocasionado la ruptura de los vasos sanguíneos de los planos superiores del abdomen- se agudizó durante la fase posoperatoria y avanzó hacia una necrosis tisular de gran tamaño y a una infección grave producida por Staphylococcus aureus y Pseudomonas aeruginosa. El médico ordenó entonces diez sesiones de terapia hiperbárica, y la receta no incluyó un cubrimiento antibiótico adecuado, por cuanto no se dispuso el cultivo pertinente para identificar el germen infeccioso, y el desbridamiento de la piel ampliamente necrosada fue tardío y no controlado mediante hospitalización.

Como resultado de esta situación, se otorgó a la paciente incapacidad médica de 45 días y se presentaron secuelas, consistentes en deformidad física que afecta el cuerpo con carácter permanente.

La Corte Suprema de Justicia analizó que para el manejo del eritema, la epidermólisis, la necrosis cutánea y la infección durante el posoperatorio, de acuerdo con el protocolo terapéutico, era necesario: $i$ ) programar enseguida de la operación las citas de control -domiciliarias o en consultorio- que sean necesarias para tener pleno conocimiento acerca de la evolución o involución de su paciente, teniendo en cuenta que la primera de ellas no 
puede sobrepasar el tercer día, como quiera que es el período indispensable para que cualquier complicación empiece a hacerse notoria; ii) elaborar un diagnóstico precoz sobre el estado de salud de la persona intervenida, que permita establecer probables complicaciones y el tratamiento para seguir; iii) ante la evidencia de un profuso enrojecimiento de la piel, indicativo de eritema, iniciar el suministro de oxígeno hiperbárico (cámara e inyecciones) y aplicar cremas antibióticas hasta que se defina la lesión; iv) hacer escarectomías parciales con químicos, si la lesión es superficial para mantener limpia la piel y permitir un proceso adecuado de cicatrización; v) disponer la toma de las muestras de tejido - biopsia - con propósito de cultivo para identificar la presencia o no de infección; vi) recetar el medicamento antibiótico sensible al microorganismo causante del proceso infeccioso; vii) si la necrosis evoluciona a una fascitis necrotizante, practicar el desbridamiento o resección total de los tejidos necrosados y custodiar la evolución; viii) hacer o disponer las curaciones externas que sean necesarias para lograr una adecuada cicatrización; $i x$ ) ante la formación de queloides, hacer la resección y reparación estética (injertos si es necesario), y $x$ ) solicitar el apoyo por interconsulta que demande para la atención de las lesiones de piel o el manejo de la infección.

Concluye la Corte que si el profesional de la medicina estética cumple con los estándares mencionados, se habrá satisfecho el deber objetivo de cuidado y por modo alguno la creación o incremento del riesgo permitido podría serle atribuido. En caso contrario, y siempre que la acción disvaliosa supere el límite del riesgo típicamente relevante causando de forma próxima el resultado imputado, hay lugar a efectuar la imputación en el tipo objetivo, que fue justamente lo que acaeció en el caso en estudio.

Ahora bien, si se demuestra que el daño en la salud del paciente en el posoperatorio es el resultado de descuido del paciente o de su negligencia en seguir las indicaciones del galeno o en la atención estricta del tratamiento, se reconocerá una acción a propio riesgo y el médico no habrá superado 
el riesgo permitido, con lo cual su conducta deviene en atípica. Sobre este preciso aspecto ha señalado la jurisprudencia colombiana:

Se insiste, la conducta negligente del facultativo debe tener repercusión directa en el desvalor de resultado, pues si la lesión o la muerte de la persona sobreviene como derivación de situaciones al margen de la práctica médica o por alguna táctica distractora del tratamiento asumida por parte del paciente —autopuesta en peligro o acción a propio riesgo-, no habría lugar a imputar el delito imprudente al galeno, pues sería aquel y no este entonces, a quien se debería atribuir la contribución al desenlace transgresor del interés jurídico tutelado (Corte suprema de Justicia, Sala de Casación Penal, Proceso 33920, 11 de abril de 2012).

\section{El principio de confianza y su aplicación en la responsabilidad médica}

Este principio, que encuentra sus raíces en la jurisprudencia del Tribunal Supremo alemán para resolver temas atinentes al tráfico rodado, parte del supuesto de que cada persona pueda organizar sus actividades en el convencimiento fundado de que los demás se comportarán también de manera reglamentaria. Por ejemplo, quien atraviesa una calle presume que quien conduce un vehículo por la vía se detendrá frente a la luz roja del semáforo y, por ello, puede cruzar sin peligro para su vida o integridad personal.

En una sociedad donde existe una clara asignación de competencias se espera que cada ciudadano atienda a las expectativas que se tienen en el cumplimiento de su rol, de donde se concluye que cada individuo es responsable de las consecuencias defraudadoras de su comportamiento, esto es, cuando desatiende los criterios de convivencia social.

Ahora bien, a pesar de que este subinstituto, que es una expresión del riesgo permitido (Montealegre Lynett, 1988, p. 64), fue utilizado en principio para los temas relacionados con el tráfico automotor, hoy no existe discusión sobre el hecho de que es aplicable a todas las situaciones en que participa un número plural de personas. En consecuencia, en actividades 
complejas que requieren el concurso de varios ciudadanos, en ocasiones con conocimientos especializados, hablamos de la necesaria división del trabajo. En esta distribución de funciones se exige partir de la base de que cada cual desarrollará a conciencia su tarea (autorresponsabilidad), lo cual permite a las demás personas confiar, válidamente, en la correcta atención de los deberes jurídicos.

Si ello es así, cada persona debe responder exclusivamente por la tarea que le ha sido asignada, y se le autoriza a confiar en los que los demás, a su turno, atenderán satisfactoriamente sus propias responsabilidades. Al respecto afirma Jakobs (2007): "El principio de confianza significa que, a pesar de la experiencia de que otras personas cometen errores, se autoriza confiar - en una medida aún por determinar- en su comportamiento correcto (entendido no como suceso psicológico, sino como estar permitido confiar)" (p. 253). Como lo resume Montealegre Lynett (2003): "mientras no existan circunstancias excepcionales, se tiene derecho a esperar de los demás un comportamiento reglamentario" (p. 36).

La doctrina ha coincidido en que la actividad en la que existe una mayor posibilidad de aplicación del principio de confianza es en el campo médico, pues, sin lugar a dudas, es donde más se requiere el trabajo en equipo y una clara división de actividades de acuerdo con la especialidad que ha alcanzado la profesión. Por ello, a continuación analizaremos varias situaciones en las que tiene aplicación este instituto en la actividad médica y qué excepciones pueden pregonarse del mismo.

En el acto médico participa un equipo en el que encontramos personas que desarrollan un rol trascendente e independiente, como el cirujano y el anestesiólogo. Asimismo, otros actores desempeñan labores secundarias y dependientes, como son las enfermeras y el instrumentador quirúrgico ${ }^{2}$. En

\footnotetext{
${ }^{2}$ En ocasiones su tarea se torna en principal pues desarrolla actividades propias de su profesión tanto como circulante de quirófano como instrumentadora propiamente dicha. Su tarea comprende diversas actividades que van más allá de alcanzar los instrumentos al cirujano, tales como preparar, esterilizar y ordenar el instrumental quirúrgico. Pese a ello, además realiza funciones encomendadas y supervisadas por el cirujano como desinfectar y ocluir o vendar la herida operatoria, finalizada la intervención (Argnani, 2013, p. 124).
} 
el caso de los primeros profesionales nombrados, se pregona el principio de confianza por la existencia de una relación horizontal, esto es, "aquella que tiene lugar entre profesionales que poseen un mismo nivel de cualificación en sus respectivas ramas" (Gómez Rivero, citada por Bernate Ochoa, 2010, p. 167). Se cita como ejemplo en la literatura el médico que confía en que el anestesiólogo preparará y aplicará adecuadamente el compuesto anestésico y que realizará las maniobras de reanimación correspondientes cuando fuere necesario puesto que estas son sus funciones. De manera que, cuando el paciente fallece debido a una deficiencia en la administración de la anestesia, ya sea en la preparación del compuesto anestésico o en su aplicación, no podrá imputarse el resultado lesivo al cirujano.

También opera el principio de confianza tratándose de relaciones verticales, es decir, las existentes entre quienes tienen el rol principal y las que ostentan uno secundario y dependiente, de tal forma que el superior puede confiar en que el inferior se comportará correctamente y el inferior puede confiar en las órdenes del superior. Se cita como ejemplo que, cuando el médico solicita a la enfermera aplicar un medicamento específico, el facultativo puede confiar en que aplicará la sustancia que fue indicada y en la cantidad prescrita. A su vez, la enfermera puede confiar en que la orden dada por el médico se ajusta a la lex artis. Por ejemplo, si un médico le indica a una enfermera que debe aplicar una determinado medicamento al paciente y este muere por una reacción alérgica a ella, lo cual era previsible, solo responderá penalmente el primero, pues la enfermera que contribuyó causalmente a la producción del resultado no infringió ningún deber de cuidado porque su actuación estaba dentro del riesgo permitido. Sin lugar a dudas, el principio de confianza es una expresión del peligro socialmente tolerado.

De otra parte, para que pueda aceptarse el principio de confianza en las relaciones verticales es imprescindible la correcta preparación e instrucciones por parte del superior a sus auxiliares. Este predicado no es viable cuando el inferior se encuentra bajo la vigilancia del superior, como sucede con el estudiante que realiza un procedimiento con la tutela de su profesor. En este 
caso, el deber de cuidado está dirigido precisamente a la vigilancia, control o cuidado del comportamiento de otras personas. Tampoco opera el principio de confianza cuando es evidente el incumplimiento del rol por parte del destinatario del principio de confianza, en lo que se ha conocido como la presencia de circunstancias excepcionales, como cuando el instrumentador se encuentra en evidente estado de embriaguez o, en general, en condiciones de inferioridad física o síquica por el cansancio, la droga, etc. En esta situación debe ser reemplazado o de lo contrario se responderá conjuntamente con él, en caso de cualquier fallo técnico (principio de defensa).

Cuando se permite la delegación de funciones, el delegante debe ejercer vigilancia sobre el cumplimiento de las tareas por el delegado. Con todo, es importante advertir que la inobservancia del deber de supervisar que se asigna al director del tratamiento no exime al colaborador de la responsabilidad que surja de la ejecución inadecuada de sus responsabilidades. Pues como lo advierte la doctrina (Argnani, 2013), como sujetos de derecho que son, cada participante deberá responder por las consecuencias de los actos que constituyan sus propias tareas, no pudiendo justificar sus errores en una falta de control (p. 133).

Existen en la doctrina algunos casos que se han considerado paradigmáticos en la aplicación del principio de confianza en la actividad médica. Nos referimos al abandono de compresas en el cuerpo del paciente ${ }^{3}$; la aplicación de nuevas técnicas en la cirugía estética ${ }^{4}$;

\footnotetext{
${ }^{3}$ La Corte Suprema de Justicia de Colombia, en Sentencia del 18 de mayo de 2005, M. P. Jaime Alberto Arrubla Paucar, precisó que en los eventos en que en el cuerpo del paciente se dejen compresas u otros elementos quirúrgicos, se debe declarar como responsables a todos los participantes en el evento salvo que logren demostrar que no son responsables del hecho. En materia penal se sostiene que los profesionales que se encuentran en la sala de cirugía pueden confiar en que quien realiza el conteo de la compresas lo hará correctamente y no se podrá exigir a los demás que verifiquen la situación (Bernate Ochoa, 2010, p. 173; Solórzano Garavito, 2014, p. 112).

${ }^{4}$ Se presenta la situación cuando se aplica por parte del cirujano una nueva técnica que viene probando, pero que aún no cuenta con aceptación científica. Cuando el paciente muere y se vincula penalmente también al anestesiólogo, en concepto de la doctrina este debe ser absuelto por el principio de confianza (Solórzano Garavito, 2014, p. 112; Bernate Ochoa, 2010, p. 174).
} 
la utilización del electrobisturí5; y el empleo de capacidades ajenas ${ }^{6}$, entre otros.

\section{El consentimiento informado}

Consiste en "la aquiescencia o autorización que da el paciente para que el médico realice un determinado procedimiento, después que este le ha explicado en términos que le sean entendibles, en qué consiste el procedimiento, qué efectos se van a derivar del mismo, cuáles son los riesgos objetivos que genera, qué otras alternativas distintas existen" (Solórzano Garavito, 2014, p. 143).

Históricamente se conocen dos visiones sobre el tratamiento de los pacientes; una de carácter paternalista y otra autonomista. La primera, le da primacía a la posición del médico en la medida en que como este es quien sabe, es el que puede tomar decisiones. La segunda, privilegia la autonomía del paciente. La Corte Constitucional de Colombia ha señalado como regla general que el médico no puede actuar sin el consentimiento del paciente, partiendo del reconocimiento de la libertad y autonomía del hombre y en la aplicación de sus atributos de autodeterminación y disponibilidad. Robustece su posición el alto tribunal con lo preceptuado en los artículos 1 y 15 de la Ley 23 de 1981 que indican:

\footnotetext{
${ }^{5}$ Para la utilización de este equipo que genera gran rendimiento, en algunas operaciones es necesario colocar al paciente dos placas con gel para lograr el adecuado contacto. Terminada la operación se detecta que la persona sufrió una quemadura en las zonas de contacto. Verificado el procedimiento, se establece que la persona encargada cumplió satisfactoriamente con los requerimientos de la utilización del equipo. En este evento, en razón a que por el principio de confianza los participantes en el acto médico obraron confiando en que el equipo estaba en óptimas condiciones, deben ser liberados de responsabilidad penal (Solórzano Garavito, 2014, p. 114; Bernate Ochoa, 2010, p. 174).

${ }^{6}$ Cuando un paciente debe ser intervenido, es necesario contar con exámenes de laboratorio previos y en el curso del procedimiento se debe aplicar anestesia. Por principio de confianza, no será responsable el cirujano cuando los exámenes están mal practicados o el anestesiólogo se equivoca en cuanto a la calidad y cantidad de la anestesia, salvo que existan situaciones excepcionales como el estado de embriaguez del anestesiólogo o se conozca que el laboratorio presenta recurrentes fallas.
} 
El médico debe considerar y estudiar al paciente como persona que es, en relación con su entorno, con el fin de diagnosticar la enfermedad y sus características individuales y ambientales, y adoptar medidas curativas y de rehabilitación correspondientes, [de modo que] ...pedirá su consentimiento para aplicar los tratamientos médicos y quirúrgicos que considere indispensables y que puedan afectarlo física o psíquicamente, salvo en los casos en que ello no fuere posible, y le explicará al paciente $\mathrm{o}$ a sus responsables de tales consecuencias anticipadamente. (Sentencia T-477, 23 de octubre de 1995). ${ }^{7}$

Instrumentos de carácter internacional se han preocupado por el criterio del consentimiento informado, basta citar la Declaración sobre la Promoción de los Derechos de los Pacientes en Europa, del año de 1994, promovida por la Organización Mundial de la Salud; el Convenio para la Protección de los Derechos Humanos y la Dignidad del Ser humano con respecto a las Aplicaciones de la Biología y la Medicina-Consejo de Europa-del 4 de abril de 1997, y la Declaración Universal sobre el Genoma Humano y los Derechos Humanos —Unesco- del 11 de noviembre de 1997 (Araque Moreno, 2014).

Ahora bien, en materia de consentimiento informado, es uniforme la doctrina al afirmar que existen tres clases: el directo o personal, el sustituto y el mixto (sustituto y judicial). El primero, se presenta cuando el propio paciente, después de haber recibido toda la información correspondiente en términos que le permitan entender el procedimiento al que va a ser sometido y los riesgos del mismo, autoriza actuar; el segundo es el que es dado por una persona distinta a la que va a ser atendida, cuando legalmente esta no lo puede emitir, como es el caso de los padres a nombre de sus hijos, o el de los tutores frente a los mentalmente incapaces o personas en

\footnotetext{
${ }^{7}$ Se trata de un niño a quien un perro le cercenó el pene y los testículos. Los médicos proyectaron que académicamente sería interesante realizarle un cambio de sexo y posteriormente obtuvieron el consentimiento de los padres, quienes dibujaron su firma en un escrito en el que autorizaron "cualquier tipo de tratamiento (incluyendo el cambio de sexo) que conlleve a mejorar la situación actual de nuestro hijo", sin que fueran conscientes de la trascendencia del cambio de sexo del hijo. La Corte entiende que en este caso no se obtuvo en debida forma el consentimiento informado del paciente por lo que ordena realizar una readecuación del sexo y que la menor pueda ser nuevamente varón. (Bernate Ochoa, 2010, p. 128).
} 
estado de inconciencia. En algunos eventos, cuando por razones extremas el consentimiento por sustitución no puede ser otorgado por un tercero en los términos anotados en precedencia, se puede acudir al llamado consentimiento presunto $^{8}$. Por último, el consentimiento mixto se presenta cuando, además del consentimiento de los padres, se requiere una autorización judicial, como en el caso de los oligofrénicos que deben ser sometidos a ciertos procedimientos que podrían ser lesivos para sus derechos, a procrear, por ejemplo, pero deben ser sometidos a ellos para evitar embarazos futuros. En casos como el comentado ha dicho la Corte Constitucional colombiana:

Pero además de que dicho consentimiento sea informado y cualificado en algunas ocasiones se requiere que este consentimiento se acompañe igualmente del agotamiento previo de algunos trámites judiciales por medio de los cuales se autorice la práctica de algún procedimiento médico, particularmente cuando, como consecuencia de la práctica del mismo, se vaya a decidir de manera definitiva sobre alguna función orgánica de una persona, es decir, cuando se vaya a afectar o limitar severamente una capacidad funcional, alterando incluso de manera definitiva algún derecho del menor o del disminuido mental que ha sido sustituido en su consentimiento.

En estas eventualidades, es necesario tener la certeza absoluta que la persona que va a ser sustituida en su consentimiento, no vaya a tener a futuro, la posibilidad de adquirir el criterio suficiente y racionalidad de su condición personal, que le permita en algún momento dado, otorgar su consentimiento. (Sentencia T-1019, 1 de diciembre de 2006)

Ahora bien, existen situaciones excepcionales en las que el médico puede actuar sin el consentimiento del paciente. El artículo 14 de la Ley 23 de 1981 preceptúa que en Colombia: "El médico no intervendrá quirúrgicamente

\footnotetext{
${ }^{8}$ Dice Argnani que: "en términos estrictamente penales, la figura del consentimiento presunto se sitúa entre el consentimiento expreso (del que se diferencia por ser una causa de justificación y una construcción normativa, y no una efectiva manifestación de voluntad) y el estado de necesidad justificante (del que se diferencia en que la justificación, en este caso, no depende de una ponderación objetiva de intereses, sino de la voluntad hipotética del bien jurídico afectado) y se considera una causa de exclusión del injusto penal limitada al derecho penal".
} 
a menores de edad, a personas en estado de inconsciencia o mentalmente incapaces, sin la previa autorización de sus padres, tutores o allegados, a menos que la urgencia del caso exija una intervención inmediata".

De esta norma se colige que es viable proceder sin el consentimiento del paciente en tres casos: urgencias (consentimiento presunto), cuando el estado del paciente no sea normal o se encuentre en condición de inconciencia y carezca de parientes o allegados que lo suplan, y cuando el paciente sea menor de edad y no exista familiar que pueda dar el consentimiento.

En cuanto al consentimiento, este debe ser libre, voluntario y, además, debe plantearse en forma tal que el paciente esté en condiciones de entenderlo, teniendo en cuenta entre otros aspectos, el conocimiento especializado del médico y el conocimiento lego del paciente. De esta forma, el galeno a cargo del tratamiento debe informar en forma completa, clara e inteligible para que el paciente efectivamente pueda comprender su trascendencia y significado cuando otorga el correspondiente consentimiento, así como sus respectivas consecuencias.

Afirma la doctrina que cuando el tratamiento no es de naturaleza curativa, por ejemplo, en el caso de una cirugía estética, la información que se suministra al paciente debe ser mucho más rigurosa y extenderse, de paso, a la posibilidad de que no se alcance el efecto esperado (Araque Moreno, 2014, p.142).

Ahora bien, puede suceder que el paciente no quiera enterarse de la enfermedad que lo aqueja y se rehúse a someterse al tratamiento. En este evento, el médico debe analizar si la enfermedad puede afectar a otras personas - por ejemplo, a la pareja del paciente en el caso del sida- y debe tomar las medidas necesarias para neutralizar el riesgo en cuestión, por ejemplo, informando sobre este aspecto a la esposa o compañera para que tomen las precauciones de rigor (p. 142).

En conclusión, como lo advierte Argnani (2013): “Por disposición legal, la autorización informada del enfermo se convierte en otra de las pautas que delimitan el riesgo tolerado en materia médica" (p. 257). 


\section{a. Consecuencias penales de la omisión del consentimiento informado}

Si aceptamos que compartimos el enfoque de la autonomía, podemos afirmar que cuando el médico procede a un tratamiento sin el consentimiento informado o cuando el mismo no sea válido por carecer de alguno de los requisitos que le son propios, el profesional de la medicina debe responder penalmente por el daño ocasionado, por ejemplo, por unas lesiones personales o un delito de homicidio culposo'.

Bien puede suceder que no exista consentimiento informado o que este sea inválido, pero que el procedimiento resulte exitoso. En este evento, puede afirmarse que ninguna responsabilidad penal le es endilgable al médico. Pueden surgir sanciones de orden administrativo, propias de los tribunales de ética médica. Con todo, algunas legislaciones como las de Paraguay (Código Penal, art. 123), Portugal (Código Penal, art. 156) y Austria consideran este hecho como una "intervención médica arbitraria".

En los casos en que se tenga el consentimiento informado y este sea válido pero el tratamiento devenga ineficaz, a pesar de que el galeno haya ajustado su conducta a las reglas de la lex artis, se le exonera de responsabilidad penal pues su conducta es atípica por no haber superado el riesgo permitido. A contrario sensu, cuando se le haya otorgado válidamente el consentimiento informado, pero la práctica médica haya sido incorrecta y como consecuencia se produzca una consecuencia nociva para la vida o la salud del paciente, al médico se le puede imputar la producción del resultado a título de culpa por imprudencia y, sostienen algunos autores, a título de dolo eventual (Araque Moreno, 2014).

\footnotetext{
9 Zaffaroni engloba los actos médicos adecuados a la lex artis en los supuestos de atipicidad conglobante. Explica que el médico está obligado a obtener la autorización del paciente, pero que la falta de esta solo le acarrea responsabilidad administrativa, pudiendo acarrear la penal si configura algún tipo de delito contra la libertad personal, pero jamás tipicidad penal de lesiones, porque el fin terapéutico excluye estas intervenciones del ámbito de prohibición del tipo de lesiones. (Citado por Argnani, 2013, p. 251).
} 


\section{Imputación o autopuesta en peligro del paciente}

En la relación médico-paciente surgen unas responsabilidades recíprocas que imponen al galeno desplegar todo su conocimiento y capacidad para salvar y recuperar la salud del paciente y a este último, permitir que el médico actúe y cumplir estrictamente con las recomendaciones efectuadas para lograr su recuperación. Cuando el paciente desatiende estas instrucciones o limita el actuar del profesional y de ello se deriva un resultado lesivo, debe asumir las consecuencias de su conducta, en lo que se ha llamado en la teoría de la imputación objetiva una acción a propio riesgo, equivalente a la autopuesta en peligro.

En la casuística, se conoce en Colombia el caso de los testigos de Jehová que, por respetables creencias, no admiten transfusiones de sangre. De acuerdo con su convicción, se tiene que nacer y morir con la propia sangre, porque así lo ordena Jehová. Esto implica que si se requiere hacer uso de la sangre en desarrollo de un procedimiento quirúrgico, el testigo de Jehová le da como alternativa al médico que use el plasma, que es un derivado de la sangre. En esta situación, si durante un procedimiento se produce la muerte por no utilizar la sangre de que se dispone, no se podrá imputar el resultado al profesional, pues se trata de una clásica acción a propio riesgo.

También puede suceder que sea el médico quien siga las creencias de los testigos de Jehová y frente a una situación como la comentada se niegue a efectuar la transfusión de sangre al paciente, evento en el cual se crea por el médico un riesgo jurídicamente desaprobado y debe responder por las consecuencias lesivas en caso de producirse.

Otra situación relacionada con las acciones a propio riesgo en la actividad médica se produce con los enfermos terminales que padecen grandes dolores que son insoportables y deterioran su calidad de vida, lo cual los conduce a solicitar su derecho a morir, en razón de no llevar una vida digna. Este es un tema ampliamente tratado por la doctrina. Así, José Luis Díez Ripollés ha precisado: 
La preeminencia de la voluntad o interés del afectado debe regir de modo general; sin duda está presente en todas las hipótesis en que se precisa la solicitud o consentimiento expresos o tácitos del afectado, o en las que se parte de una voluntad plasmada previamente en una declaración vital. (Citado por Solórzano Garavito, 2014, p. 131)

A su turno, el profesor Juan Carlos Carbonell señala: "La petición expresa y seria de morir de un ser humano ha de ser atendida de tal manera que su consideración ha de sobreponerse a cualquier valoración positiva que pueda merecer la continuidad de la vida" (citado por Solórzano Garavito, p. 131).

En Colombia, el tema ha sido estudiado por la Corte Constitucional en dos sentencias paradigmáticas. En una primera oportunidad, se demandó la constitucionalidad del artículo 326 del Código Penal de 1980, que consagraba el homicidio por piedad ${ }^{10}$. En esta decisión (Sentencia C-239, 20 de 1997) se declaró la exequibilidad de la norma, por cuanto a pesar de la finalidad altruista con la que se procedía, el comportamiento seguía siendo antijurídico y tenía una pena disminuida.

No obstante, en la misma decisión, se dejó sentado que cuando el médico atiende a la voluntad del paciente que sufre de una enfermedad terminal que le produce grandes padecimientos y que no desea alargar su vida dolorosa, la conducta del sujeto agente carece de antijuridicidad. Al respecto afirmó la Alta Corporación:

No sobra recordar que el consentimiento del sujeto pasivo debe ser libre, manifestado inequívocamente por una persona con capacidad de comprender la situación en que se encuentra. Es decir, el consentimiento implica que la persona posee información seria y fiable acerca de su enfermedad y de las opciones terapéuticas y su pronóstico, y cuenta con la capacidad intelectual suficiente para tomar la decisión. Por ello, la Corte concluye que el sujeto activo debe ser un médico, puesto que es el único profesional capaz no solo

\footnotetext{
${ }^{10}$ Hoy este homicidio degradado se encuentra consagrado en el artículo 106 del Código Penal Colombiano (Ley 599 de 2000).
} 
de suministrar esa información al paciente sino además de brindarle las condiciones para morir dignamente. Por ende, en los casos de enfermos terminales, los médicos que ejecuten el hecho descrito en la norma penal con el consentimiento del sujeto pasivo no pueden ser, entonces, objeto de sanción y, en consecuencia, los jueces deben exonerar de responsabilidad a quienes así obren. (Sentencia C-239, 20 de mayo de 1997)

Al revisar una acción de tutela, la Corte Constitucional colombiana volvió a ocuparse del tema en la Sentencia T-970 de 15 de diciembre de 2014. En esta ocasión, si bien no pudo resolver el asunto en estudio, pues la persona que solicitaba se autorizara la eutanasia murió en el curso del proceso, es decir, operó la carencia de objeto por daño consumado, la Corporación aprovechó para revisar la figura de la eutanasia, reiterando los criterios establecidos en la decisión de 1997, pero haciendo claridad sobre los siguientes presupuestos para hacer efectivo el derecho a morir dignamente, el cual declaró como derecho fundamental: i) el padecimiento de una enfermedad terminal que produzca intensos dolores. ii) el consentimiento libre, informado e inequívoco. Finalmente, exhortó al Ministerio de Salud para que, mientras el Congreso cumple su responsabilidad de regular el tema, esa instancia del poder ejecutivo diseñe y planee una ruta para que se garantice la muerte digna a los colombianos en todos los hospitales y clínicas del país, de esta forma, debe constituir un comité que realice el seguimiento a estos procedimientos.

De otra parte, el incumplimiento de las obligaciones del paciente que genera una autopuesta en peligro se presenta también cuando la persona no cumple las recomendaciones del médico para que asista a determinados controles, se tome algunos medicamentos, se realice los exámenes de rigor y tenga algunas precauciones especiales, por ejemplo no exponerse al sol cuando ha sido operado para resolver un problema de miopía. Otra posibilidad de responsabilidad del paciente se genera cuando este omite decir la verdad acerca de sus síntomas o antecedentes (Poveda Buitrago, 2014, p. 169). 


\section{Realización del riesgo}

Al iniciar la presente contribución afirmamos que para el juicio de imputación no es suficiente que se genere un riesgo desaprobado, sino que se requiere como un elemento fundamental que el mismo se concrete en un resultado lesivo como resultado de dicho riesgo. Es decir, se excluye la imputación cuando el resultado se produce, no como consecuencia del peligro creado por el autor, sino solo en conexión casual con el mismo. Como lo ejemplifica la doctrina, alguien dispara a la mano de una persona que siendo hemofílica fallece a consecuencia de esa herida (De Jesús, 2006, p. 103).

Bajo este criterio, podemos recopilar algunos supuestos que propone el profesor Eduardo Montealegre Lynett (1988) en los que se compromete la responsabilidad de los profesionales de la medicina cuando el resultado se produce por una conducta imprudente o negligente del médico a pesar de no ser la causa del riesgo inicial (p. 26).

En un accidente de tránsito una persona recibe lesiones leves que, generalmente no conducen a resultados más graves. Por culpa de un mal tratamiento se produce la muerte o una lesión mayor. El resultado más grave solo se le imputa al galeno y no al conductor.

Un sujeto le ocasiona a otra persona una herida con aptitud suficiente para producir la muerte. Existiendo aún la posibilidad de salvación, el herido es conducido al hospital, donde muere porque el médico no interviene o lo hace en forma defectuosa. Aquí se afirma que el médico creó un nuevo riesgo con su conducta descuidada. El agresor responde por tentativa de homicidio y el médico por homicidio culposo.

Otro evento se presenta cuando el médico acelera la producción de un resultado que era inevitable. Por ejemplo, cuando el paciente presenta una enfermedad incurable pero por una conducta imprudente o negligente del galeno se apresura el deceso. En este evento, responde por homicidio. 


\section{Referencias}

Araque Moreno, D. (2012). El consentimiento informado y su trascendencia en el Derecho Penal. Revista Nuevo Foro Penal, 10(82), 132-147. Medellín: Universidad EAFIT.

Argnani, P. I, (2013). Responsabilidad penal del médico. Buenos Aires: Astrea.

Bernate Ochoa, F. (2010). Imputación objetiva y responsabilidad penal médica. Bogotá: Universidad del Rosario.

Código Penal colombiano. Ley 599 de 2000 (24 de julio). Congreso de la República. Diario Oficial 44097 de 24 de julio.

Código Penal de la Nación Argentina. Ley 11179 de 1921 (30 de septiembre). Congreso de la Nación. Boletín Oficial 8300 de 3 de noviembre.

Colombia. Corte Constitucional (23 de octubre de 1995). Sentencia T-477. Expediente T-65087. M. P. Alejandro Martínez Caballero.

Corte Constitucional (20 de mayo de 1997). Sentencia C-239. Expediente 1490. M. P. Carlos Gaviria Díaz

Corte Constitucional (15 de diciembre de 2014). Sentencia T-970 Expediente T-4067849. M. P. Luis Ernesto Vargas Silva.

Corte Suprema de Justicia, Sala de casación Penal (11 de abril de 2012). Proceso 33920. Aprobado acta 121. M. P. Augusto José Ibáñez Guzmán.

Corte Suprema de Justicia, Sala de Casación Penal (29 de junio de 2016). Proceso 41245. Aprobado acta 194. M. P. José Luís Barceló Camacho

Decreto 3380 de 2004 (30 de noviembre). Por el cual se reglamenta la Ley 23 de 1981. Presidencia de la República. Diario Oficial 35914 de 30 diciembre.

Ley 23 de 1981 (18 de febrero). Por la cual se dictan normas en materia de ética médica. Congreso de la República. Diario Oficial 35711 de 27 de febrero. De Jesús, D. E. (2006). Imputación objetiva. Montevideo: B de F.

Jakobs, G. (2007). Derecho penal. Parte general. Fundamentos y teoría de la imputación, trad. Joaquín Cuello Contreras y José Luis Serrano de Murillo. Madrid: Marcial Pons.

Molina Arrubla, C. M. (1998). Responsabilidad penal en el ejercicio de la actividad médica (2. ${ }^{a}$ ed.). Medellín: Biblioteca Jurídica DIKE.

Montealegre Lynett, E. (1988). La culpa en la actividad médica, imputación objetiva y deber de cuidado. Bogotá: Universidad Externado de Colombia.

(2003). El riesgo permitido en la actividad bancaria. El caso especial de lavado de activos en Colombia (Estudio introductorio). En A. L. Callegari. El delito de blanqueo de capitales en España y Brasil. Bogotá, Universidad Externado de Colombia

Poveda Buitrago, N. (2014), Imputación objetiva acciones a propio riesgo y responsabilidad penal médica en Colombia. Bogotá: Grupo Editorial Ibáñez.

Quijano Gómez, J. O. (2012). La teoría de la imputación objetiva en los casos de culpa en la actividad médica: una aproximación teórica. Dos mil tres mil, 3(14), 47-59. Ibagué: Universidad de Ibagué. 


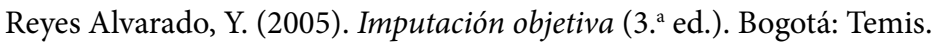

Roxin, C. (1997). Derecho penal. Parte general. Madrid: Thomson-Civitas.

Solórzano Garavito, C. R. (2014). Derecho penal y responsabilidad médica en Colombia (2. ed.). Bogotá: Nueva Jurídica. 